\title{
Revolutionary Culture: Continuity and Changes, edited by Mark Darlow
}

\section{Paola Perazzolo}

\section{(2) OpenEdition}

1 Journals

\section{Edizione digitale}

URL: https://journals.openedition.org/studifrancesi/45864

DOI: 10.4000/studifrancesi.45864

ISSN: 2421-5856

\section{Editore}

Rosenberg \& Sellier

\section{Edizione cartacea}

Data di pubblicazione: 1 octobre 2007

Paginazione: 445-446

ISSN: 0039-2944

\section{Notizia bibliografica digitale}

Paola Perazzolo, «Revolutionary Culture: Continuity and Changes, edited by Mark Darlow», Studi Francesi [Online], 152 (LI | II) | 2007, online dal 30 novembre 2015, consultato il 24 novembre 2021. URL: http:// journals.openedition.org/studifrancesi/45864 ; DOI: https://doi.org/10.4000/studifrancesi.45864

Questo documento è stato generato automaticamente il 24 novembre 2021.

\section{(c) (i) (9)}

Studi Francesi è distribuita con Licenza Creative Commons Attribuzione - Non commerciale - Non opere derivate 4.0 Internazionale. 


\title{
Revolutionary Culture: Continuity and Changes, edited by Mark Darlow
}

\author{
Paola Perazzolo
}

\section{NOTIZIA}

Revolutionary Culture: Continuity and Changes, «Nottingham French Studies», vol. 45, n. 1, spring 2006, edited by Mark DARLow, pp. 116.

1 Come ha indicato Mona Ozouf, la Rivoluzione indica da un lato una rottura violenta con il passato, dall'altro un ritorno ciclico alle origini. Una rapidissima evoluzione delle abitudini culturali - abolizione dei privilegi dei teatri, allargamento sociale del pubblico, aumento quantitativo delle pièces, eterogeneità delle forme adottate, diversa funzione attribuita all'arte, evoluzione socio-culturale legata all'espansione di nuove forme di comunicazione quali il giornalismo e i pamphlets - comporta un'altrettanto veloce e più o meno radicale modifica dei paradigmi estetici. È dunque il rapporto tra continuità e cambiamento che i contributi del presente volume vogliono prendere in considerazione, analizzando i modi «in which the Revolution treated the cultural forms and structures of the preceding period» (p. 2).

2 Katherine ASTBURY, Une Chaumière et un cœur simple: Pastoral fiction and the art of persuasion 1790-92 (pp. 5-19), esamina tre testi di Marmontel, Bernardin de Saint-Pierre e Florian pubblicati tra il 1790 e il 1792. L'autrice mostra come i temi e le immagini tradizionali utilizzati non tendano tanto a perpetuare un modello letterario preesistente o a esprimere una volontà nostalgica e/o di evasione ma testimonino di un'utopica proiezione di rigenerazione; l'immagine idillica della chaumière si pone così in relazione con l'attualità, esplicitando come il rinnovamento della nazione passi attraverso quello dei legami familiari. Come già dimostrato altrove e contrariamente a quanto sostenuto da una doxa diffusa, in Public entertainment and Theatre during the Old Regime and the French Revolution: A quantitative analysis of Play Titles (pp. 20-41), Catherine BOSLEY e Emmet KENNEDY sottolineano la continuità tra il teatro rivoluzionario e la 
produzione precedente. Così come si evince dall'esame dei titoli, la maggior parte delle pièces del decennio non mettono direttamente in scena avvenimenti legati all'attualità, eccezion fatta per le opere degli anni 1793-1794, periodo in cui la fortissima ingerenza del potere politico influenza una produzione altrimenti probabilmente meno impegnata. Francesco Paolo Alexandre MADONIA, Un aspect négligé de la conscience esthétique révolutionnaire: La Laideur des Patois (pp. 42-51), rivela come l'opposizione giacobina ai patois, considerati come esempio di laideur estetica e morale, riecheggi posizioni classiche, apportando così una dimostrazione ulteriore di quanto la retorica rivoluzionaria sia debitrice verso le strutture classiche. David mCCALLAM, The volcano: From Enlightenment to Revolution (pp. 52-68), analizza invece la metafora del vulcano quale appare prima e dopo il 1789 a livello estetico, politico e letterario, per segnalare come il suo utilizzo in alcuni testi di fine secolo - per indicare il sublime, l'immagine dell'oratore, la catarsi rivoluzionaria, ecc. - «emerge - and diverge - from the culture of the late Enlightenment» (p. 52). In L'inscription de l'actualité dans le théâtre révolutionnaire (pp. 69-76), Béatrice DIDIER prende in considerazione alcune pièces che presentano forti rimandi all'attualità. Così come aveva già suggerito in Écrire la Révolution, l'autrice mostra come le opere teatrali del periodo, mescolando toni, temi e arti, destabilizzino e inventino generi diversi da quelli tradizionali. Mark DARLOW, Staging the Revolution: the Fait historique (pp. 77-88), si interessa al genere della pièce de circonstance. Genere prevalente durante il Terrore, che pretende di trovare la sua legittimazione attraverso la celebrazione di eventi storici tratti da un passato locale e recente, ripudiando invece l'ideologicamente sospetta storia dell'Ancien Régime e rendendo così problematico il rapporto tra passato e presente storico. È invece la relazione tra storia e letteratura che interessa Daniel HALL. In Fictionalizing History and Historicizing Fiction: Émigrés, Politics and Literature (pp. 89-103), l'autore evidenzia come alcuni romanzi d'emigrazione - genere caratterizzato da grandi sperimentazioni formali - «produce uncertain answers about how literature can reflect an extraordinary reality» e come sia tuttavia «important that they are beginning to ask questions about it and their own art» (p. 103). Chiude il volume il lavoro di Malcolm соок, Utopian Fiction of the French Revolution (pp. 104-114), che fa vedere quanto un genere ben preesistente al 1789 come il racconto utopico riceva nuova linfa dal contesto rivoluzionario. Partendo da un'attualità spesso scottante i testi utopici evocati dall'autore, comici o satirici, presentano sia mondi immaginari perfetti in cui la felicità dei cittadini è garantita da governi efficaci, sia mondi meno perfetti i cui difetti rimandano allegoricamente a quelli ben noti della Francia monarchica. Interessante per il fil rouge che lo origina - la riflessione sui rapporti di continuità e rottura tra Ancien Regime e Rivoluzione -, il presente volume apporta nuovi elementi alla conoscenza di un periodo letterario che, nonostante il rinnovo di interesse degli ultimi quindici anni, resta ancora poco conosciuto. 